\title{
Glucocorticoid receptor-binding characteristics in severe asthma
}

\author{
C. Bonnans, P. Chanez, H. Meziane, P. Godard, J. Bousquet, I. Vachier
}

Glucocorticoid receptor-binding characteristics in severe asthma. C. Bonnans, P. Chanez, H. Meziane, P. Godard, J. Bousquet, I. Vachier. (C) ERS Journals Ltd 2003.

ABSTRACT: The cellular mechanisms associated with severe asthma are still poorly understood. This study investigated the association between glucocorticoid-receptor (GR) alterations and continuous oral glucocorticoid therapy requirement in severe asthma.

GR-binding affinity $\left(\mathrm{Kd}_{\mathrm{d}}\right.$ and receptor number (n) in peripheral blood monocytes (PBM) obtained from 10 normal subjects, 10 untreated, intermittent asthmatics and 10 severe asthmatics were assessed. Moreover, one ability of dexamethasone to inhibit regulated on activation, T-cells expressed and secreted (RANTES) release by these cells in vitro was investigated. GR-binding characteristics were studied in PBM using a ${ }^{3} \mathrm{H}$ dexamethasone ligand-binding assay and Scatchard analysis. RANTES release was measured in the supernatant of PBM at $24 \mathrm{~h}$ using an enzyme-linked immunosorbent assay.

No significant differences in $K_{d}$ and $n$ were found between the three groups of patients. Dexamethasone in vitro was able to inhibit RANTES release (mean \pm SEM), with the same concentration/response curve in intermittent, untreated asthmatics $(0.47 \pm 0.22$ versus $\left.1.64 \pm 0.31 \mathrm{ng} \cdot \mathrm{mL}^{-1}\right)$ and severe asthmatics $\left(1.49 \pm 0.64\right.$ versus $\left.2.59 \pm 0.77 \mathrm{ng} \cdot \mathrm{mL}^{-1}\right)$.

This study showed that, despite long-term treatment with oral glucocorticoids, there was no evidence of abnormalities in glucocorticoid receptor-binding characteristics in severe asthma, and moreover, it was demonstrated that glucocorticoid receptors were functional in vitro.

Eur Respir J 2003; 21: 985-988.
Clinic of Respiratory Illness, INSERM U454IFR 3, Arnaud de Villeneuve Hospital, CHUMontpellier, France.

Correspondence: I. Vachier

INSERM U454

Hôpital Arnaud de Villeneuve

371 Av du Doyen Gaston Giraud

34295 Montpellier Cedex 5

France

Fax: 33467521848

E-mail: vachier@montp.inserm.fr

Keywords: Binding-assay technique glucocorticoid receptor

monocytes

severe asthma

Received: July 82002

Accepted after revision: February 62003

This study was supported by the Direction de la Recherche Clinique, CHU Montpellier, France.
Glucocorticoids are the most potent anti-inflammatory agents and are widely used in the treatment of asthma [1]. Although glucocorticoid therapy efficiently controls asthma in most patients, some asthmatic subjects fail to respond and are termed "steroid-resistant" [2, 3]. In addition, another subpopulation of asthmatics is called "glucocorticoid-dependent" or severe because they require long-term systemic glucocorticoids to achieve adequate control [4]. They differ from steroidresistant patients, as they can improve their lung function after a short course of oral glucocorticoids.

Several hypotheses have been proposed to explain chronic oral glucocorticoid requirement in severe asthma, but this process is still poorly understood. One possibility concerns a potential abnormality in glucocorticoid receptor (GR)binding characteristics. Several studies have shown abnormalities in these parameters in severe asthmatics. An alteration of GR-binding characteristics has been documented in peripheral blood mononuclear cells (PBMC) [5, 6], but no studies have been performed on isolated blood monocytes from severe asthmatics.

In the present study, the characteristics of GR binding on isolated peripheral blood monocytes (PBM) have been investigated using a whole-cell, competitive-binding assay. This study was performed with ${ }^{3} \mathrm{H}$ dexamethasone on PBM from normal subjects and intermittent-untreated asthmatics compared with severe asthmatics. The in vitro glucocorticoid response was investigated by evaluation of the release of regulated on activation, T-cells expressed and secreted (RANTES) by PBM in the presence or absence of dexamethasone from these same patients.

\section{Subjects and methods}

\section{Subjects}

Twenty asthmatic subjects were selected according to the American Thoracic Society criteria [7]. The clinical severity of asthma was assessed according to Global Initiative for Asthma guidelines [8]. Ten subjects with intermittent, untreated asthma, taking $\beta_{2}$-agonists as required, were included. They were compared with 10 subjects with severe asthma described as glucocorticoid-dependent $[9,10]$. They were treated on a regular basis with prednisone, inhaled fluticasone, long-acting $\beta_{2}$-agonists and short-acting $\beta_{2}$-agonists as required. Plasma cortisol was measured with a competitive radioimmunoassay. Atopy was diagnosed on at least one positive skin-prick test (weal $>3 \mathrm{~mm}$ ) to common allergens from the Montpellier area (France).

Finally, 10 normal subjects were enrolled as the control group. None of them presented with bronchial or respiratory disease and/or allergy. All had a negative methacholine challenge test and negative skin-prick test.

None of the subjects participating in this study was a current smoker. All subjects signed an informed consent form and the study was approved by the ethics committee of the institute.

\section{Whole cell-binding assay}

PBM were isolated from blood by centrifugation over isotonic Percoll solutions (Pharmacia, St. Quentin en Yvelines, 
France) as described previously [11]. Cell viability and number were determined using the trypan blue exclusion test. Cell viability was always $>95 \%$. The purity of PBM obtained was $>95 \%$. After isolation, a ${ }^{3} \mathrm{H}$ dexamethasone radioligand-binding assay and Scatchard analysis was used as described previously [12] to determine GR-binding parameters of PBM. After three washes for $30 \mathrm{~min}$ to remove endogenous cortisol, PBM $\left(3 \times 10^{6}\right.$ cells $\left.\cdot \mathrm{mL}^{-1}\right)$ were exposed to different increased concentrations of tritiated dexamethasone (Amersham Life Science, Buckinghamshire, UK) ranging 7.5-80.0 $\mathrm{nM}$, in the presence or absence of a 1,000 fold excess of unlabelled dexamethasone (Sigma-Aldrich, Steinheim, Germany). Radioactivity was counted in liquid scintillation vials in a $\beta$-spectrometer (Wallac, Turku, Finland). Specific binding was calculated as the difference between the total radioactivity remaining in the cell pellet and the nonspecifically bound radioactivity at each dexamethasone concentration. The number of specific ${ }^{3} \mathrm{H}$ dexamethasonebinding sites per cell (n) and the equilibrium dissociation constant $(\mathrm{Kd})$ were either calculated according to SCATCHARD [13] or analysed by computer-assisted iterative nonlinear regression curve fitting procedures.

\section{Regulated on activation, T-cells expressed and secreted release}

Freshly isolated PBM were diluted at a concentration of $10^{6}$ cells $\cdot \mathrm{mL}^{-1}$ in medium containing $10 \%$ heat-inactivated foetal calf serum, $100 \mathrm{U} \cdot \mathrm{mL}^{-1}$ penicillin, $100 \mu \mathrm{g} \cdot \mathrm{mL}^{-1}$ streptomycin and $2 \mathrm{mM}$ glutamine. Cells were cultivated for $24 \mathrm{~h}$ in the absence or presence of dexamethasone at $0.1 \mu \mathrm{M}$.

For dexamethasone concentration/response curves on RANTES released by $\mathrm{PBM}$ and the determination of the inhibitory concentration of 50\% (IC50) of dexamethasone, PBM were incubated for $24 \mathrm{~h}$ with concentrations of dexamethasone from $10^{-5}-10^{-14} \mathrm{M}$. Dexamethasone IC50 was determined from the intersection on the abscissa corresponding to $50 \%$ of RANTES inhibition.

RANTES was measured in supernatants by quantitative sandwich enzyme immunoassays, according to the manufacturer's recommendations (R\&D Systems, Oxon, UK). The sensitivity for RANTES was $8 \mathrm{pg} \cdot \mathrm{mL}^{-1}$. Recovery of RANTES measured by spiking experiments was $97 \%$.

\section{Statistical analysis}

Demographic characteristics and RANTES release were expressed as mean \pm SEM and GR data were expressed as median (range). A nonparametric Kruskal-Wallis analysis of variance test was performed for comparison of the three groups of subjects. A paired Wilcoxon test was used to analyse the effect of dexamethasone on RANTES release. A paired t-test was used to analyse the dexamethasone concentration/response curve on RANTES release. Correlations were analysed using a Spearman rank test.

\section{Results}

The demographic characteristics of normal subjects, intermittent, untreated asthmatics and severe asthmatics are shown in table 1 .

SCATCHARD [13] analysis showed a single dexamethasonebinding site in PBM from the three groups of subjects. There was no significant difference in PBM GR affinity and GR number between groups (fig. 1). There was no relation between GR affinity and density, sex, age, forced expiratory volume in one second and plasma cortisol levels.

The effect of dexamethasone on RANTES release by PBM from severe and intermittent, untreated asthmatics is shown in figure 2. At baseline, PBM from severe asthmatics tended to release higher amounts of RANTES compared with intermittent asthmatics, but statistical analysis did not show any difference. Dexamethasone significantly inhibited RANTES release compared with basal values in intermittent $(0.47 \pm 0.22$ versus $\left.1.64 \pm 0.31 \mathrm{ng} \cdot \mathrm{mL}^{-1}, \mathrm{p}<0.05\right)$ and severe $(1.49 \pm 0.64$ versus $\left.2.59 \pm 0.77 \mathrm{ng} \cdot \mathrm{mL}^{-1}, \mathrm{p}<0.01\right)$ asthmatics. The dexamethasone concentration/response curve obtained with PBM from intermittent asthmatics was similar to that for severe asthmatics with a maximal RANTES inhibition at $10^{-6} \mathrm{M}(61$ and $62 \%$ of RANTES inhibition, respectively). The dexamethasone IC50 were similar in intermittent and severe asthmatics $\left(0.3 \times 10^{-7}\right.$ and $0.5 \times 10^{-7} \mathrm{M}$, respectively).

\section{Discussion}

In the present study, differences in GR-binding affinity and in GR density were not found when comparing PBM from severe asthmatics, intermittent, untreated asthmatics and normal subjects. The authors have demonstrated that the glucocorticoid response was functional, since the addition of dexamethasone was still able to inhibit RANTES release by PBM in vitro in both groups of patients. Moreover, dexamethasone IC50 on RANTES released by PBM were similar in intermittent and severe asthmatics.

A recent study demonstrated decreased GR-binding affinity in PBMC from severe asthmatics [5, 6], whereas in this study the authors did not note any GR-binding abnormality in isolated blood monocytes from the same group of patients. The present results were consistent with those found in steroid-resistant asthma. Indeed, LANE and LEE [14] did not show any GR-binding abnormalities in blood monocytes

Table 1.-Demographic characteristics of subjects

\begin{tabular}{|c|c|c|c|}
\hline & Normal & Intermittent asthma & Severe asthma \\
\hline Subjects n & 10 & 10 & 10 \\
\hline $\mathrm{F}: \mathrm{M}$ & $7: 3$ & $6: 4$ & $4: 6$ \\
\hline Age yrs & $34.3 \pm 5.2$ & $26.1 \pm 2.2$ & $55.3 \pm 5.1 * *$ \\
\hline FEV1 \% & $102.6 \pm 3.9$ & $100.9 \pm 4.0$ & $51.3 \pm 6.0 * * *$ \\
\hline Atopy & $0 / 10$ & $10 / 10$ & $7 / 10$ \\
\hline Plasma cortisol nM & $405 \pm 42.5$ & $568.4 \pm 79.5$ & $179 \pm 60.3 * *$ \\
\hline Treatment & & $\beta_{2}$-agonists ${ }^{\#}$ & $\begin{array}{l}\text { Prednisone } 19.9 \pm 13.9 \mathrm{mg} \cdot \mathrm{day}^{-1} \\
\quad \text { Fluticasone } 2000 \mu \mathrm{g} \cdot \mathrm{day}^{-1} \\
\text { g-acting } \beta_{2} \text {-agonists } 100 \mu \mathrm{g} \text { salmeterol }\end{array}$ \\
\hline
\end{tabular}

Data are expressed as mean \pm SEM. F: females; M: males; FEV1: forced expiratory volume in one second. ${ }^{\#}$ : as required. **: p<0.01 using KruskalWallis test. ${ }^{* *}: \mathrm{p}<0.001$ using Kruskal-Wallis test. 

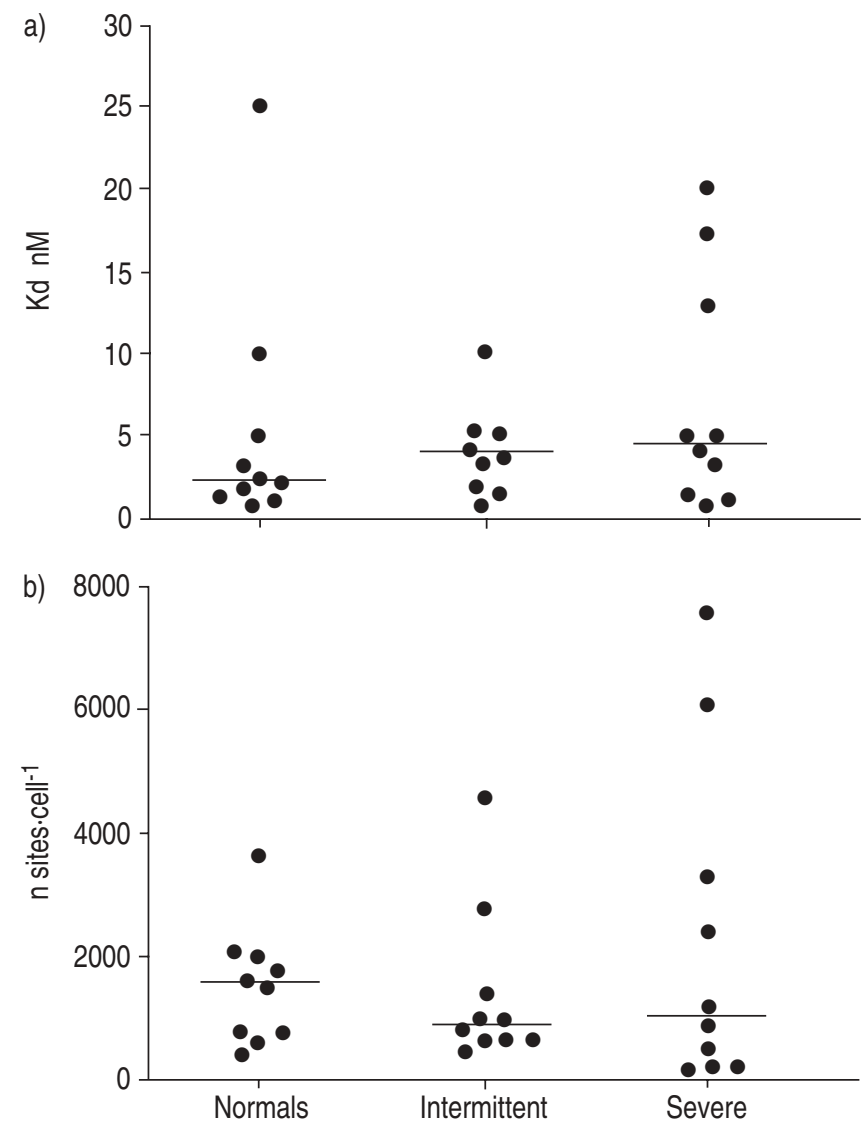

Fig. 1.-The a) glucocorticoid receptor (GR)-binding affinity ( $\mathrm{Kd})$ and b) GR number (n) of 10 normal subjects, 10 untreated, intermittent asthmatics and 10 severe asthmatics. The solid bar indicates the median for each group. $\mathrm{Kd}$ and $\mathrm{n}$ values were determined from the slope and from the intersection on the abscissa of the Scatchard plot, respectively.

from steroid-resistant asthmatics, whereas T-lymphocytes of the same patients presented a diminished GR-binding affinity and increased GR number per cell $[15,16]$. Persistent airway inflammation in severe asthma might be associated with an alteration of PBMC GR-binding affinity, as described in steroid-resistant asthma. Indeed, a diminished GR-binding affinity has been described in vitro when PBMC from normal donors were incubated with both interleukin (IL)-2 and -4 [15]. These results are restricted to T-cells, and no change in GR-binding affinity has been found in non-T-cells [15]. SHER et al. [16] observed a second population of steroid-resistant asthmatics presenting a normal-binding affinity with a markedly reduced number of GR per cell; this result concerned non-Tcells. These observations suggested that the poor response to glucocorticoids observed in severe asthma, including steroidresistant and severe asthma, could be explained in part by a diminished GR-binding affinity in blood T-lymphocytes.

One of the major characteristics of severe asthmatics is the persistence of a high level of inflammation [9, 17, 18]. The authors observed significant RANTES inhibition when studying the glucocorticoid response using the effect of dexamethasone on RANTES release. Moreover, using concentration/ response experiments, they have shown that PBM from severe asthmatics were equally sensitive to dexamethasone treatment inhibiting RANTES release than PBM from intermittent asthmatics. This result was in accordance with those described previously with IL-8 and granulocyte-macrophage colonystimulating factor [9] suggesting that, ex vivo, cells from severe
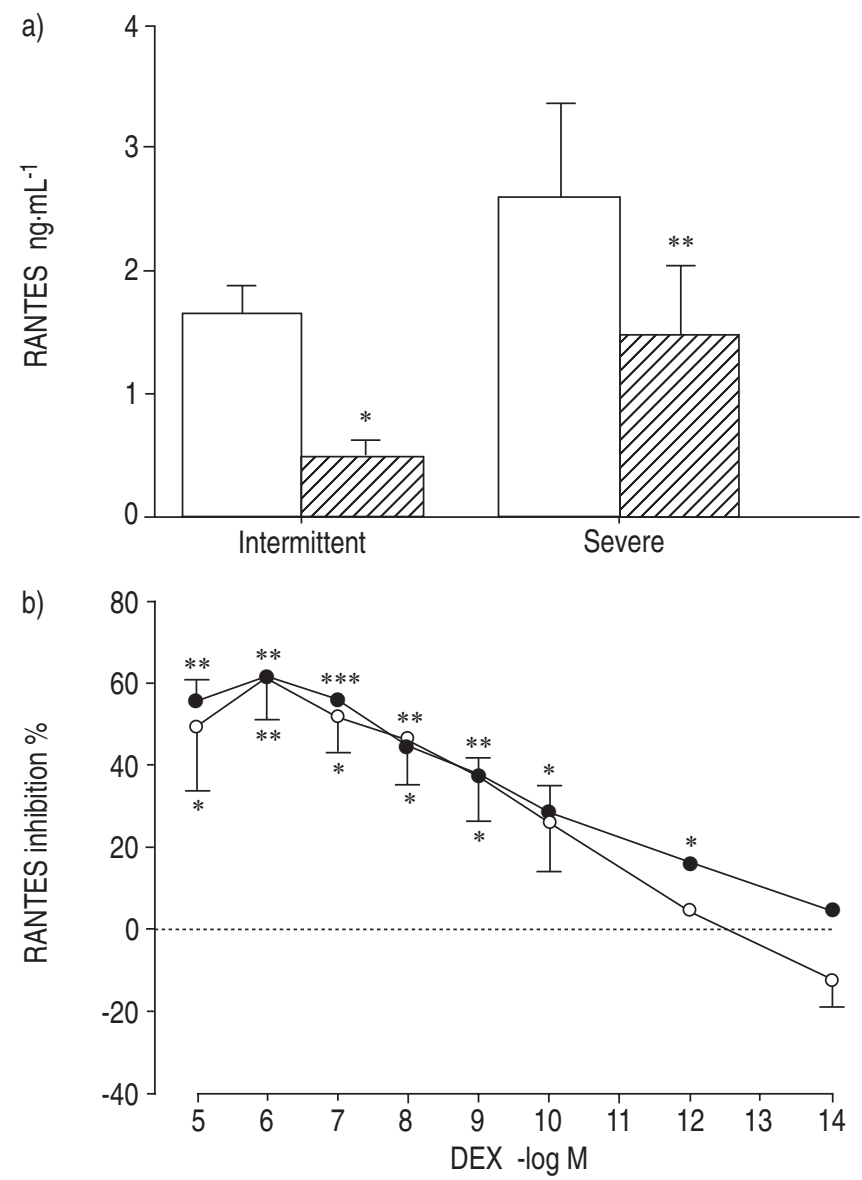

Fig. 2. - Effect of dexamethasone (DEX) treatment in vitro on regulated on activation, T-cells expressed and secreted (RANTES) release. a) Concentrations of RANTES produced by peripheral blood monocytes (PBM) isolated from 10 intermittent and 10 severe asthmatics and cultivated in the absence $(\square)$ or presence $(\mathbb{Z})$ of $0.1 \mu \mathrm{M}$ DEX for $24 \mathrm{~h}$. The results are presented as mean \pm SEM. Significant differences were determined using a paired Wilcoxon test. b) PBM from three intermittent and three severe asthmatics were cultured with different concentrations of DEX $\left(10^{-5}, 10^{-6}, 10^{-7}, 10^{-8}\right.$, $10^{-9}, 10^{-10}, 10^{-12}$ and $10^{-14} \mathrm{M}$ ) for $24 \mathrm{~h}$. RANTES was measured in cell supernatants by enzyme-linked immunosorbent assay. Results are presented as mean \pm SEM and significant differences were determined using a paired t-test. *: $\mathrm{p}<0.05$ versus baseline; ${ }^{* *}: \mathrm{p}<0.01$ versus baseline; ${ }^{* * *}: \mathrm{p}<0.001$ versus baseline.

asthmatics were sensitive to glucocorticoids by inhibiting inflammatory cytokines and chemokines.

In conclusion, the density and affinity of glucocorticoid receptors in peripheral blood monocytes of severe asthmatic patients were similar to levels noted in intermittent asthmatics and normal subjects and were not related to the glucocorticoid response in vivo. Moreover, the authors have demonstrated that glucocorticoid-receptor functionality was present in vitro. This also suggests that severity of asthma and continuous requirement to oral glucocorticoids are not mediated by a potential glucocorticoid receptor-binding abnormality in blood monocytes.

\section{References}

1. Barnes PJ. Anti-inflammatory actions of glucocorticoids: molecular mechanisms. Clin Sci 1998; 94: 557-572.

2. Carmichael J, Paterson IC, Diaz P, Crompton GK, Kay AB, Grant IW. Corticosteroid resistance in chronic asthma. Br Med J Clin Res 1981; 282: 1419-1422. 
3. Kamada AK, Leung DY, Szefler SJ. Steroid resistance in asthma: our current understanding. Pediatr Pulmonol 1992; 14: $180-186$.

4. Cypcar D, Busse WW. Steroid-resistant asthma. J Allergy Clin Immunol 1993; 92: 362-372.

5. Irusen E, Matthews JG, Takahashi A, Barnes PJ, Chung KF, Adcock IM. p38 Mitogen-activated protein kinase-induced glucocorticoid receptor phosphorylation reduces its activity: role in steroid-insensitive asthma. J Allergy Clin Immunol 2002; 109: 649-657.

6. Nimmagadda S, Spahn J, Nelson H, Jenkins J, Szefler S, Leung D. Fluticasone propionate results in improved glucocorticoid receptor binding affinity and reduced oral glucocorticoid requirements in severe asthma. Am Allergy Asthma Immunol 1998; 81: 35-40.

7. American Thoracic Society. Standards for the diagnosis and care of patients with chronic obstructive pulmonary disease (COPD) and asthma. This official statement of the American Thoracic Society was adopted by the ATS Board of Directors, November 1986. Am Rev Respir Dis 1987; 136: 225-244.

8. World Health Organization/National Heart Lung and Blood Institute. Workshop report. Global strategy for asthma management and prevention. Publication no. 953659. Bethesda, National Institutes of Health, 1995.

9. Gagliardo R, Chanez P, Vignola A, et al. Glucocorticoid receptor alpha and beta in glucocorticoid dependent asthma. Am J Respir Crit Care Med 2000; 162: 7-13.

10. Bonnans C, Vachier I, Chavis C, Godard P, Bousquet J,
Chanez P. Lipoxins are potential endogenous antiinflammatory mediators in asthma. Am J Respir Crit Care Med 2002; 165: 1531-1535.

11. Majori M, Vachier I, Godard P, Farce M, Bousquet J, Chanez P. Superoxide anion production by monocytes of corticosteroid-treated asthmatics patients. Eur Respir J 1998; 11: $133-138$

12. Crabtree G, Smith K, Munck A. Glucocorticoid Receptors. New York, Churchill Livingstone, 1981.

13. Scatchard G. The attractions of proteins from small molecules and ions. Ann NY Acad Sci 1949; 51: 660.

14. Lane S, Lee T. Glucocorticoid receptor characteristics in monocytes of patients with corticosteroid-resistant bronchial asthma. Am Rev Respir Dis 1991; 143: 1020-1024.

15. Kam J, Szefler S, Surs W, Sher E, Leung D. Combination IL-2 and IL-4 reduces glucocorticoid receptor-binding affinity and T cell response to glucocorticoids. J Immunol 1993; 151: 3460-3466.

16. Sher E, Leung D, Surs W, et al. Steroid-resistant asthma. Cellular mechanisms contributing to inadequate response to glucorticoid therapy. J Clin Invest 1994; 93: 33-39.

17. Wenzel S, Szefler S, Leung D, Sloan S, Rex M, Martin R. Bronchoscopic evaluation of severe asthma: persistent inflammation associated with high dose glucocorticoids. Am J Respir Crit Care Med 1997; 156: 737-743.

18. Vachier I, Chiappara G, Vignola A, et al. Glucocorticoid receptors in bronchial epithelial cells in asthma. Am J Respir Crit Care Med 1998; 158: 963-970. 